\title{
The role of blood groups in the development of diabetes mellitus after gestational diabetes mellitus
}

This article was published in the following Dove Press journal:

Therapeutics and Clinical Risk Management

19 October 2015

Number of times this article has been viewed

\author{
Hatice Karagoz' \\ Abdulsamet Erden ${ }^{2}$ \\ Ozerhan Ozer ${ }^{2}$ \\ Kubra Esmeray ${ }^{2}$ \\ Ali Cetinkaya ${ }^{2}$ \\ Deniz Avci² \\ Samet Karahan ${ }^{2}$ \\ Mustafa Basak ${ }^{2}$ \\ Kadir Bulut ${ }^{2}$ \\ Hasan Mutlu ${ }^{3}$ \\ Yasin Simsek ${ }^{4}$ \\ 'Internal Medicine Department, \\ Acıbadem Kayseri Hospital, \\ ${ }^{2}$ Internal Medicine Department, \\ ${ }^{3}$ Medical Oncology Department, \\ ${ }^{4}$ Endocrinology Department, Kayseri \\ Training and Research Hospital, \\ Kayseri,Turkey
}

Correspondence: Abdulsamet Erden Internal Medicine Department, Kayseri Training and Research Hospital, Hastane street, Kayseri 38010 , Turkey

Tel +905327803805

Email drsameterden@hotmail.com
Introduction: Gestational diabetes mellitus (GDM) is a common condition that is defined as glucose intolerance of varying degree with onset or first recognition during pregnancy and it affects approximately $5 \%$ of all pregnancies all over the world. GDM is not only associated with adverse pregnancy outcomes such as macrosomia, dystocia, birth trauma, and metabolic complications in newborns, but it is also a strong predictor of transitioning to overt DM postpartum. The association of ABO blood groups with DM has been observed before in several epidemiological and genetic studies and resulted with inconsistent findings, but still there are not enough studies in the literature about the association of ABO blood groups with GDM. In this study, we aimed at investigating any possible relationship between the $\mathrm{ABO}$ blood group system and GDM and also the transitioning of GDM to overt DM postpartum, in Turkey.

Patients and methods: A total of 233 patients with GDM from Kayseri Training and Research Hospital between 2002 and 2012 were included in the study. The cases that have serologically determined blood groups and $\mathrm{Rh}$ factor in the hospital records were included in the study, and the patients with unknown blood groups were excluded. Patients were classified according to blood groups (A, B, AB, and $\mathrm{O}$ ) and Rh status (+/-). GDM was diagnosed based on the glucose cut-points of the International Association of the Diabetes and Pregnancy Society Groups. The distributions of blood groups of the patients with GDM were compared with the distribution of blood groups of 17,314 healthy donors who were admitted to the Turkish Red Crescent Blood Service in our city in 2012 .

Results: There was a significant difference between the patients with GDM and control group in terms of distribution of $\mathrm{ABO}$ blood groups. Blood group $\mathrm{AB}$ was found to be higher in the patients with GDM compared to the control group $(P=0.029)$. When the patients were compared according to the development of $\mathrm{DM}$, the ratio of group $\mathrm{O}$ was higher than others, while the ratio of group B was lower in the group developing DM $(P=0.001)$. There was a significant difference between the groups - GDM patients with or without DM - in terms of distribution of $\mathrm{ABO}$ blood groups with $\mathrm{Rh}$ factor and the ratio of developing $\mathrm{DM}$ is found to be higher in patients with $+\mathrm{Rh}$ factor among all the blood groups except for group $\mathrm{B}(P=0.008)$.

Conclusion: In this study, we found a higher risk of GDM for the patients with blood group AB, which means that we have to be more careful on the follow-up of pregnant women with blood group $\mathrm{AB}$. The patients with GDM of blood group $\mathrm{O}$ are under a higher risk of developing $\mathrm{DM}$ and also $+\mathrm{Rh}$ factor must be considered as another risk factor, so these patients should be closely followed postpartum by the oral glucose tolerance tests. To our knowledge, this is the first analysis that investigates the association between the ABO blood groups and transitioning to DM after GDM

Keywords: gestational diabetes mellitus, $\mathrm{ABO}$ blood groups, $\mathrm{Rh}$ factor 


\section{Introduction}

Gestational diabetes mellitus (GDM) is a common condition that is defined as glucose intolerance of varying degree with onset or first recognition during pregnancy. ${ }^{1}$ GDM affects approximately $5 \%$ of all pregnancies all over the world and 135,000 pregnancies per year in the USA. Its incidence is increasing in parallel with the global increase in obesity and Type 2 diabetes mellitus (T2DM). ${ }^{2}$ GDM is not only associated with adverse pregnancy outcomes such as macrosomia, dystocia, birth trauma, and metabolic complications in newborns, but it is also a strong predictor of transitioning to overt DM postpartum. ${ }^{3,4}$

There are many screening tests defined by different associations for to determine GDM. A $50 \mathrm{~g}$ oral glucose challenge test (GCT) is the most widely accepted screening method for GDM in North America. ${ }^{5}$ The American Diabetes Association (ADA) published new recommendations for the detection and diagnosis of GDM in 2011, and these new criteria were based on the consensus opinion of the International Association of the Diabetes and Pregnancy Society Groups (IADPSG). ${ }^{6}$ IADPGS and ADA recommends a $75 \mathrm{~g} \mathrm{GCT}$ for screening at 24-28 weeks' gestation and a diagnosis of GDM is made when one or more glucose values fall at or above the specified thresholds: fasting glucose level: $\geq 5.1 \mathrm{mmol} / \mathrm{L}(92 \mathrm{mg} / \mathrm{dL}), 1$ hour: $\geq 10.0 \mathrm{mmol} / \mathrm{L}$ (180 mg/dL), 2 hours: $\geq 8.5 \mathrm{mmol} / \mathrm{L}$ (153 mg/dL).

The ABO blood group system was first discovered by Karl Landsteiner in 1900. The blood group of a person depends upon the presence or absence of two genes, A and B. The gene is located on chromosome 9 and is called ABO glycosyltransferase. ${ }^{7}$

No diseases are known to result from the lack of expression of ABO blood group antigens, but the susceptibility to a number of diseases has been interrelated to ABO phenotype. For example, gastric cancer is found to be more common in blood group A individuals, whereas gastric and duodenal ulcers occur more commonly among the $\mathrm{O}$ blood group individuals. ${ }^{8}$

The association of $\mathrm{ABO}$ blood groups with $\mathrm{DM}$ has been observed before in several epidemiological and genetic studies and resulted with inconsistent findings. ${ }^{8-11}$ Group A was found to be associated with DM in some studies, but still there is not enough study in the literature about the correlation of ABO blood groups with GDM. ${ }^{12,13}$ In this study, we aimed at investigating any possible relationship between the $\mathrm{ABO}$ blood group system and GDM, in Turkey. In the second part of the study, we examined the relationship between the $\mathrm{ABO}$ blood group system and transitioning of GDM to overt DM postpartum.

\section{Patients and methods}

A total of 233 patients with GDM from Kayseri Training and Research Hospital between 2002 and 2012 were included in the study. This study was approved by the Kayseri Training and Research Hospital Ethics Committee. The cases that have serologically determined blood groups and $\mathrm{Rh}$ factor in the hospital records were included in the study, and the patients with unknown blood group were excluded. Patients were classified according to blood groups $(\mathrm{A}, \mathrm{B}, \mathrm{AB}$, and $\mathrm{O})$ and Rh status (+/-). All women had a GCT at 24-28 gestational weeks, and the patients with results of 2-hour plasma glucose level $\geq 140$ were offered a $75 \mathrm{~g}$ oral glucose tolerance test (OGTT). GDM was diagnosed based on the glucose cut-points of the IADPSG criteria, that is, when any of the following glucose values was exceeded: fasting plasma glucose level $\geq 5.1 \mathrm{mmol} / \mathrm{L}(92 \mathrm{mg} / \mathrm{dL})$ and/or 1-hour plasma glucose level $\geq 10 \mathrm{mmol} / \mathrm{L}(180 \mathrm{mg} / \mathrm{dL})$ and/or 2-hour plasma glucose level $\geq 8.5 \mathrm{mmol} / \mathrm{L}(153 \mathrm{mg} / \mathrm{dL})$. The patients who did not meet the diagnostic criteria were excluded.

The distributions of blood groups of the patients with GDM were compared with the distribution of blood groups of healthy donors that admitted to the Turkish Red Crescent Blood Service in our city in 2012. Donors consisted of 17,314 healthy volunteers. After comparing with the healthy control group, the patients with the diagnosis of GDM were examined for transitioning to overt DM postpartum by checking their drugs from the pharmacy data system in our country or by calling and inviting them to the hospital for the fasting glucose levels. The patients with fasting glucose levels $\geq 126 \mathrm{mg} / \mathrm{dL}$ at least twice or taking pharmacy for diabetes were accepted as DM.

Statistical analysis was performed using the SPSS software version 16.0 (SPSS Inc., Chicago, IL, USA). Qualitative variables are given as percent and for the correlation of the patients with GDM and control group from the point of $\mathrm{ABO}$ blood groups. The relationship between the groups of GDM and DM patients following GDM was examined by the chi-square test. A $P$-value $<0.05$ was considered significant.

\section{Results}

The mean age of all patients with GDM was $32.45 \pm 5.14$ years. The percentages of patients with GDM for O, A, B, and $\mathrm{AB}$ groups were $26 \%, 45 \%, 17 \%$, and $12 \%$, whereas those of control group (healthy donors) were $31 \%, 45 \%, 16 \%$, and $8 \%$, respectively. In both of the groups, the ratio of the patients with blood group A was the highest, while the ratio of group $\mathrm{AB}$ was the lowest (Table 1). There was a significant 
Table I Comparison of $A B O$ blood groups between the patients with GDM and control groups

\begin{tabular}{llll}
\hline $\begin{array}{l}\text { ABO blood } \\
\text { groups }\end{array}$ & $\begin{array}{l}\text { Patients with } \\
\text { GDM, n (\%) }\end{array}$ & $\begin{array}{l}\text { Control } \\
\text { group, n (\%) }\end{array}$ & P-value \\
\hline 0 & $60(26)$ & $5,423(31)$ & 0.029 \\
A & $104(45)$ & $7,756(45)$ & \\
B & $40(17)$ & $2,819(16)$ & \\
AB & $29(12)$ & $1,316(8)$ & \\
Total & $233(100)$ & $17,314(100)$ & \\
\hline
\end{tabular}

Abbreviation: GDM, gestational diabetes mellitus.

difference between the patients with GDM and control group in terms of distribution of $\mathrm{ABO}$ blood groups and the percentage of group $\mathrm{AB}$ was found to be higher in patients with GDM compared to the control group $(P=0.029)$.

The percentages of $\mathrm{O}, \mathrm{A}, \mathrm{B}$, and $\mathrm{AB}$ groups were $22 \%$, $47 \%, 19 \%$, and $12 \%$ in GDM patients without DM, whereas those of patients with DM following GDM were 56\%, 28\%, $0 \%$, and $16 \%$, respectively. Of the 233 patients with GDM, 25 patients have developed DM postpartum. There was a significant difference between the groups in terms of distribution of $\mathrm{ABO}$ blood groups, and the ratio of group $\mathrm{O}$ was higher in the group developing DM after GDM, while the ratio of group B was lower ( $P=0.001$; Table 2$)$.

When comparing the blood group $\mathrm{O}$ with non- $\mathrm{O}(\mathrm{B}, \mathrm{AB}$, and A) blood groups, the odds for developing DM after GDM were found to be $1.2(14 / 11)$ and $0.28(46 / 162)$, respectively. We calculated the risk ratio as $(0.56 / 0.22=2.54)$ and the odds ratio as $(1.2 / 0.28=4.28)$.

The percentages of $\mathrm{ORh}(+), \mathrm{ORh}(-), \mathrm{ARh}(+), \mathrm{ARh}(-)$, $\mathrm{B} \mathrm{Rh}(+), \mathrm{B} \mathrm{Rh}(-), \mathrm{AB} \mathrm{Rh}(+)$, and $\mathrm{AB} \mathrm{Rh}(-)$ groups were $19 \%$, $3 \%, 40 \%, 7 \%, 17 \%, 2 \%, 9 \%$, and $3 \%$ in the GDM patients without DM, whereas those of GDM patients with DM were $48 \%$, $8 \%, 20 \%, 8 \%, 0 \%, 0 \%, 16 \%$, and $0 \%$, respectively (Table 3). There was a significant difference between the groups - GDM patients with or without DM - in terms of $\mathrm{ABO}$ blood groups with $\mathrm{Rh}$ factor, and as listed in Table 3 , the ratio of developing $\mathrm{DM}$ is found to be higher in patients with $+\mathrm{Rh}$ factor among all the blood groups except for group $\mathrm{B}(P=0.008)$.

Table 2 Comparison of ABO blood groups between the GDM patients with or without T2DM

\begin{tabular}{llll}
\hline $\begin{array}{l}\text { ABO blood } \\
\text { groups }\end{array}$ & $\begin{array}{l}\text { GDM patients } \\
\text { with DM, n (\%) }\end{array}$ & $\begin{array}{l}\text { GDM patients } \\
\text { without DM, n (\%) }\end{array}$ & P-value \\
\hline 0 & $14(56)$ & $46(22)$ & 0.001 \\
A & $7(28)$ & $97(47)$ & \\
B & $0(0)$ & $40(19)$ & \\
AB & $4(16)$ & $25(12)$ & \\
Total & $25(100)$ & $208(100)$ & \\
\hline
\end{tabular}

Abbreviations: GDM, gestational diabetes mellitus; T2DM, type 2 diabetes mellitus.

\section{Discussion}

The pathogenesis of GDM is not yet completely defined. Genetic predispositions, environmental factors, and their interactions that are blamed for T2DM may also be the causes of GDM. Genetic variants related to regulation of insulin secretion and resistance were found to be significantly associated with a higher risk of GDM, in a meta-analysis. ${ }^{14}$ New studies on the roles of biomarkers for T2DM and GDM aimed at resolving the uncertainty on the pathogenesis of GDM. ${ }^{15-17} \mathrm{~A}$ study showed that the inflammation markers such as tumor necrosis factor-alpha and interleukin-6 could play a role in insulin resistance and development of GDM. ${ }^{17}$ Another study showed that the increase of inflammatory markers may be one of the first detectable disorders in healthy women at high risk of T2DM and insulin-resistance syndrome like those with a GDM history. ${ }^{18}$ Another study that aimed at evaluating the value of increasing inflammation in predicting GDM showed that maternal white blood cell, erythrocyte, and platelet counts are important correlates of GDM. ${ }^{19}$ Soluble cell adhesion molecules such as sE-selectin and sICAM-1 could be the markers of endothelial dysfunction that was reported to be a plausible important step in insulin resistance and T2DM, and so the elevated levels of these molecules might represent an early manifestation of endothelial dysfunction and independently predict development of T2DM. ${ }^{16}$ These biomarkers could also be implicated in the pathogenesis of GDM because of the similarity in pathogenesis between T2DM and GDM. ${ }^{14}$ There are many studies about the association of DM and $\mathrm{ABO}$ blood group systems in the literature. McConnell et a ${ }^{12}$ showed an association between DM and blood group A and this was confirmed by Andersen and Lauritzen. ${ }^{13} \mathrm{~A}$ recent study has demonstrated that blood group $\mathrm{B}$ is a protective factor against T2DM. ${ }^{11}$ A study from India showed an association of increased risk of $\mathrm{DM}$ and blood groups of $\mathrm{A}$ and $\mathrm{AB} .{ }^{10}$ A study consisting of 792 Iranian pregnant women observed that women with blood group $\mathrm{AB}$ had higher fasting blood glucose in the second trimester than those with blood group A. ${ }^{20}$ But still there are not enough studies in the literature about the association of $\mathrm{ABO}$ blood groups with GDM. Because of the increasing prevalence of GDM and DM after GDM, we aimed at investigating any possible relationship between the ABO blood group system and GDM and also transitioning to DM.

Different percentages have been reported on GDM progression to T2DM postpartum in the literature depending on ethnicity and the proportion of participants with severe hyperglycemia during pregnancy. In a study Jang stated that 9\% of predominantly Hispanic women with GDM developed 
Table 3 Comparison of ABO blood groups and Rh factor between the GDM patients with or without DM

\begin{tabular}{lll}
\hline ABO blood groups with Rh factor & GDM patients with DM, n (\%) & GDM patients without DM, n (\%) \\
\hline O Rh $(+)$ & $12(48)$ & $39(19)$ \\
O Rh $(-)$ & $2(8)$ & $7(3)$ \\
A Rh $(+)$ & $5(20)$ & $84(40)$ \\
A Rh $(-)$ & $2(8)$ & $13(7)$ \\
B Rh $(+)$ & $0(0)$ & $36(17)$ \\
B Rh $(-)$ & $0(0)$ & $4(2)$ \\
AB Rh $(+)$ & $4(16)$ & $19(9)$ \\
AB Rh $(-)$ & $0(0)$ & $6(3)$ \\
Total & $25(100)$ & $208(100)$ \\
\hline
\end{tabular}

Abbreviation: GDM, gestational diabetes mellitus.

T2DM in early postpartum while this ratio as $3 \%$ in a study population of predominantly white women and $10 \%$ in a population of predominantly black women. ${ }^{4}$ Furthermore, another author reported a $10 \%$ rate of developing DM in a population of predominantly black women. ${ }^{4}$

In our retrospective examination of 233 patients with GDM, AB blood group seems to be a risk factor for the development of GDM. This finding was in contrast with a recent study from the People's Republic of China. This study was a prospective cohort study of Chinese women and demonstrated that the women with blood group $\mathrm{AB}$ were less likely to have a positive GCT and GDM. ${ }^{21}$ These contrasting findings suggest that the association between the ABO blood groups and the risk of DM and GDM may differ by populations.

Among the patients with GDM, there was a significant risk of developing DM after GDM for the blood group $\mathrm{O}$ and a relative mild increase for the blood group $\mathrm{AB}$.

On the other hand, the lower risk of developing DM after GDM among the patients with blood group B seems to be a protective factor at this point. Further studies are needed to understand the underlying biological base and the biological processes responsible for this protective effect.

Prior studies on the association of Rh factor with the risk of T2DM were rare and reported in consisted findings. ${ }^{9,10}$ Our study showed that Rh status is also another effective factor together with blood groups and $+\mathrm{Rh}$ factor could increase the risk for developing DM after GDM.

GDM is not only associated with acute increased risk for complications of pregnancy but also it has been associated with long-term disease risks for both mother and baby. ${ }^{2}$ Perinatal morbidity includes hyperinsulinaemia, macrosomia, hypoglycemia, hyperbilubinaemia, and respiratory distress syndrome, whereas long-term morbidity for the offspring includes obesity and diabetes independent of genetic factors, so it is important to determine all the etiological factors responsible for GDM in the follow-up of these patients. ${ }^{2}$
Our study has some limitations. The first one being the retrospective nature of study and the other important limitation is the lack of knowledge about the following risk factors for postpartum DM: prepregnancy weight, body mass index, previous history of GDM, and a family history of DM in first-degree relatives.

Because the $\mathrm{ABO} / \mathrm{Rh}$ blood group phenotypes are stable throughout life time, it is important to determine the association between the ABO blood groups and the risk of GDM because of the clinical implications. If our findings of this study can be replicated by other studies performed on other nations in larger patient populations, ABO blood group phenotypes may be used as a single risk factor or in combination with other risk factors to identify individuals at high risk for possible prevention of GDM before or at early pregnancy. However, further epidemiological and genetic studies are necessary to define the relationship between the ABO blood groups and GDM.

\section{Conclusion}

In summary, this study found that the patients with blood group $\mathrm{AB}$ have a higher risk for GDM when the screening tests are performed among the normal population. This means that we have to be more careful on the follow-up of pregnant women with blood group AB. OGTT may be performed at earlier gestational weeks, or the patients may be invited to the hospital for glucose monitoring during the pregnancy, even if OGTT is normal.

Especially the patients with GDM of blood group $\mathrm{O}$ are under the higher risk of developing $\mathrm{DM}$ and also $+\mathrm{Rh}$ factor must be remembered as another risk at this point, so these patients should be closely followed postpartum by the OGTTs.

To our knowledge, this is the first analysis that investigates the association between the $\mathrm{ABO}$ blood groups and transitioning to DM after GDM. 


\section{Disclosure}

The authors report no conflicts of interest in this work.

\section{References}

1. Rajput R, Yadav Y, Nanda S, Rajput M. Prevalence of gestational diabetes mellitus \& associated risk factors at a tertiary care hospital in Haryana. Indian J Med Res. 2013;137(4):728-733.

2. Rice GE, Illanes SE, Mitchell MD. Gestational diabetes mellitus: a positive predictor of type 2 diabetes. Int J Endocrinol. 2012;2012:721653.

3. Yang SJ, Kim TN, Baik SH, et al. Insulin secretion and insulin resistance in Korean women with gestational diabetes mellitus and impaired glucose tolerance. Korean J Intern Med. 2013;28:306-313.

4. Jang HC. Gestational diabetes in Korea: incidence and risk factors of diabetes in women with previous gestational diabetes. Diabetes Metab J. 2011;35:1-7.

5. Donovan L, Hartling L, Muise M, Guthrie A, Vandermeer B, Dryden DM. Screening tests for gestational diabetes: a systematic review for the U.S. preventive services task force. Ann Intern Med. 2013;159(2):115-123.

6. Nankervis A, McIntyre HD, Moses RG, Ross GP, Callaway LK. Testing for gestational diabetes mellitus in Australia. Diabetes Care. 2013;36(5):e64.

7. Farhud DD, Yeganeh MZ. A brief history of human blood groups. Iranian J Publ Health. 2013;42(1):1-6.

8. Kamil M, Al-Jamal HA, Yusoff NM. Association of ABO blood groups with diabetes mellitus. Libyan J Med. 2010;5.

9. Okon UA, Antai AB, Osim EE, Ita SO. The relative incidence of diabetes mellitus in $\mathrm{ABO} /$ Rhesus blood groups in South-Eastern Nigeria. Niger J Physiol Sci. 2008;23(1-2):1-3.

10. Sidhu LS, Malhotra P, Singh SP. ABO and Rh blood groups in diabetes mellitus. Anthropol Anz. 1988;46(3):269-275.
11. Qi L, Cornelis MC, Kraft P, et al. Genetic variants in ABO blood group region, plasma soluble E-selectin levels and risk of type 2 diabetes. Hum Mol Genet. 2010;19(9):1856-1862.

12. McConnell R, Pyke D, Roberts JAF. Blood groups in diabetes mellitus. Br Med J. 1956;1:772-776.

13. Andersen J, Lauritzen E. Blood groups and diabetes mellitus. Diabetes. 1960;9:20-24

14. Zhang $\mathrm{C}$, BaoW, Rong $\mathrm{Y}$, et al. Genetic variants and the risk of gestational diabetes mellitus: a systematic review. Hum Reprod Update. 2013;19(4):376-390.

15. Hu FB, Meis JB, Li TY, Rifai N, Manson JE. Inflammatory markers and risk of developing type 2 diabetes in women. Diabetes. 2004;53(3): 693-700.

16. Meigs JB, Hu FB, Rifai N, Manson JE. Biomarkers of endothelial dysfunction and risk of type 2 diabetes mellitus. JAMA. 2004;291(16): 1978-1986.

17. Gomes CP, Torloni MR, Gueuvoghlanian-Silva BY, Alexandre SM, Mattar R, Daher S. Cytokine levels in gestational diabetes mellitus: a systematic review of the literature. Am J Reprod Immunol. 2013; 69(6):545-557.

18. Di Benedetto A, Russo GT, Corrado F, et al. Inflammatory markers in women with a recent history of gestational diabetes mellitus. $J$ Endocrinol Invest. 2005;28(1):34-38.

19. Yang H, Zhu C, Ma Q, Long Y, Cheng Z. Variations of blood cells in prediction of gestational diabetes. J Perinat Med. 2015;43(1):89-93.

20. Seyfizadeh N, Seyfizadeh N, Yousefi B, et al. Is there association between $\mathrm{ABO}$ blood group and the risk factors of unfavorable outcomes of pregnancy? J Matern Fetal Neonatal Med. 2014;17:1-5.

21. Zhang $\mathrm{C}, \mathrm{Li} \mathrm{Y}$, Wang $\mathrm{L}$, et al. Blood group $\mathrm{AB}$ is protective factor for gestational diabetes mellitus: a prospective population-based study in Tianjin, China. Diabetes Metab Res Rev. 2015;31(6):627-637.
Therapeutics and Clinical Risk Management

\section{Publish your work in this journal}

Therapeutics and Clinical Risk Management is an international, peerreviewed journal of clinical therapeutics and risk management, focusing on concise rapid reporting of clinical studies in all therapeutic areas, outcomes, safety, and programs for the effective, safe, and sustained use of medicines. This journal is indexed on PubMed Central, CAS,

\section{Dovepress}

EMBase, Scopus and the Elsevier Bibliographic databases. The manuscript management system is completely online and includes a very quick and fair peer-review system, which is all easy to use. Visit http://www.dovepress.com/testimonials.php to read real quotes from published authors. 